\title{
Iron Deficiency in the Rat: Effects on Phenylalanine Metabolism
}

\author{
BRUCE MACKLER, RICHARD PERSON, LOUISE R. MILLER, AND C. A. FINCH
}

Departments of Pediatrics and Medicine, and the Center for Child Development and Mental Retardation, University of

Washington, Seattle, Washington, USA

\section{Summary}

Concentrations of phenylalanine in the plasma were markedly elevated in iron-deficient rats and appeared to vary directly with the degree of iron deficiency. Plasma concentrations of phenylalanine returned to control levels within one week after treatment of the iron-deficient rats with iron dextran. The elevated levels of plasma phenylalanine were probably not produced by a deficiency in liver phenylalanine hydroxylase because levels of activity of the enzyme were found to be normal in the livers of the iron-deficient animals.

\section{Speculation}

The finding of increased plasma levels of phenylalanine suggests that phenylalanine metabolism may be impaired in iron-deficient rats with concomitant increases in compounds formed by alternate pathways of phenylalanine metabolism such as phenylpyruvic acid which may disturb mental function.

Previously, the authors have shown that activities of brain aldehyde oxidase, an important iron-containing enzyme in the pathway of serotonin degradation, were significantly reduced in iron-deficient rats (4). Concomitantly, concentrations of serotonin and total 5-hydroxyindole compounds increased in the brain tissue of the iron-deficient animals. Aldehyde oxidase activities and concentrations of 5-hydroxyindole compounds in brain tissue returned to normal levels $1 \mathrm{wk}$ after treatment of the iron-deficient animals with iron dextran.

The present study was undertaken to study the effects of iron deficiency on the metabolism of phenylalanine because phenylalanine hydroxylase, another iron-containing enzyme (1), is necessary for the conversion of phenylalanine to tyrosine. Decreases in the tissue levels of the enzyme due to iron deficiency may lead to accumulation of phenylalanine and its toxic byproducts in the blood with impairment of mental function as seen in phenylketonuria (2).

\section{MATERIALS AND METHODS}

Male Sprague-Dawley rats were obtained at 4 wk of age, 1 wk after weaning. Rats to be made iron deficient were given a low iron diet, prepared in our laboratory as described by ICN Nutritional Biochemicals, Cleveland, $\mathrm{OH}$, that contained $10 \mathrm{mg}$ iron/ $\mathrm{kg}$. After 1 month on this diet, the hemoglobin concentration of those animals receiving it was determined and studies were performed only on rats with blood hemoglobin concentrations of less than $7 \mathrm{~g} / 100 \mathrm{ml}$. Two groups of control animals were used. One group was fed Purina Laboratory Chow (Ralston Purina Co., Inc., St. Louis, MO) containing $382 \mathrm{mg}$ of iron per $\mathrm{kg}$ throughout the experimental period, and the other group was fed the low iron diet during the experimental period, but received weekly ip injections of $5 \mathrm{mg}$ of iron dextran (Imferon iron, kindly supplied by Lakeside Laboratories, Inc., Milwaukee, WI). All animals were allowed food and water ad libitum. At the end of the experimental period ( 1 month) the control animals receiving the iron-deficient diet and weekly injections of iron dextran weighed on the average approximately $15 \%$ more than the iron-deficient rats and had eaten approximately $15 \%$ more diet daily.

Phenylalanine concentrations in the blood were determined by the method of McCaman and Robins (5). Studies of the activity of phenylalanine hydroxylase in liver were performed with an oxygen polarograph at $25^{\circ}$ as follows. Rats were sacrificed by cervical dislocation and the livers were quickly removed and weighed, and homogenized with 9 volumes of cold $0.15 \mathrm{M} \mathrm{KCl}$ solution. The suspension was then centrifuged at $5^{\circ}$ in a Sorvall refrigerated centrifuge for $15 \mathrm{~min}$ at $16,000 \mathrm{Xg}$. The supernatant solution was stored in ice and assayed as follows for enzymatic activity. $\mathrm{H}_{2} \mathrm{O}, 1.3 \mathrm{ml}, 0.2 \mathrm{ml}$ of $1 \mathrm{M}$ potassium phosphate solution of $\mathrm{pH} 6.8,0.1 \mathrm{ml}$ of a $0.1 \mathrm{M}$ solution of dithiothreitol (DTT), 0.2 $\mathrm{ml}$ of the liver supernatant fraction and $0.02 \mathrm{ml}$ of a $75 \mathrm{mM}$ solution of 6,7 ,dimethyl-5,6,7,8-tetrahydropterin were added to the chamber of the oxygen polarograph and the blank rate of oxygen uptake was determined. Assays were then begun by addition of $0.05 \mathrm{ml}$ of a $0.1 \mathrm{M}$ solution of phenylalanine.

DTT was obtained from Sigma Chemical Co., St. Louis, MO and tetrahydropterin from Aldrich Chemical Co., Milwaukee, WI. Protein was determined by the method of Lowry et al. (3). Hemoglobin was determined as cyanmethemoglobin with standards employed for calibration (Hycel, Inc., Houston, TX). Statistical analyses were performed by standard methods as described by Snedecor and Cochran (8).

\section{RESULTS AND DISCUSSION}

The effects of iron deficiency and treatment with iron dextran on phenylalanine concentrations in rat plasma are shown in Table 1. Initial values of blood phenylalanine concentrations were obtained immediately before placing the animals on the low iron diets. Values for plasma phenylalanine and hemoglobin concentrations were again determined after the rats had been on the diet 1 month (iron-deficient levels) and again $1 \mathrm{wk}$ after an ip injection of iron dextran (treated levels), which was given each animal after the 1 month iron-deficient samples of blood were obtained. As shown in Table 1, the animals showed a marked and significant $(P<0.001)$ increase in concentrations of plasma phenylalanine when iron deficient, with some levels increasing by over $100 \%$ of the control values. One week after treatment with iron dextran, the levels of plasma phenylalanine in the animals had decreased to concentrations not significantly different from the initial values $(P>0.1)$. In similar studies of the two control groups, rats fed either a Purina rat chow diet or the low iron diet supplemented with weekly ip injections of iron dextran showed no significant changes in plasma phenylalanine concentrations over the 5-wkperiod from the initial levels.

Values were calculated from the data in Table 1 for the percent of increase in plasma phenylalanine concentrations produced by iron deficiency in the animals and compared with the correspond- 
Table 1. Effects of iron deficiency and treatment with iron dextran on phenylalanine concentrations in rat plasma

Phenylalanine concentration $\mathrm{mg} / 100 \mathrm{ml}$ Hemoglobin plasma 1 month iron

\begin{tabular}{ccccc}
\cline { 2 - 5 } Animal & $\begin{array}{c}\text { Initial } \\
\text { value }\end{array}$ & $\begin{array}{c}\text { Iron } \\
\text { deficient }\end{array}$ & Treated & $\begin{array}{c}\text { iron } \\
\text { deficient } \\
\text { g/100 ml } \\
\text { blood }\end{array}$ \\
\hline 1 & 2.07 & 2.41 & 2.55 & 5.9 \\
2 & 1.80 & 2.31 & 2.02 & 5.5 \\
3 & 2.01 & 2.58 & 1.94 & 6.3 \\
4 & 2.08 & 2.57 & 1.56 & 5.3 \\
5 & 1.97 & 2.60 & 2.11 & 5.0 \\
6 & 2.16 & 3.07 & & 5.6 \\
7 & 1.97 & 3.67 & 2.65 & 5.3 \\
8 & 1.86 & 3.88 & 2.46 & 5.4 \\
9 & 1.90 & 2.79 & & 5.5 \\
10 & 1.87 & 2.50 & 1.90 & 5.9 \\
11 & 2.38 & 2.97 & & 6.1 \\
12 & 1.93 & 3.29 & & 4.9 \\
13 & 1.97 & 2.66 & 1.95 & 6.2 \\
14 & 2.34 & 2.88 & 2.45 & 6.6 \\
15 & 2.04 & 2.34 & 2.34 & 6.8 \\
16 & 2.25 & 2.71 & 2.21 & 6.8 \\
Average $^{1}$ & $2.04 \pm 0.04$ & $2.83 \pm 0.12$ & $2.18 \pm 0.09$ & $5.8 \pm 0.2$ \\
\hline
\end{tabular}

' Values are the mean \pm the $S E$.

ing blood hemoglobin concentrations (all values were expressed as the averages of values within each $0.5 \mathrm{~g}$ range of hemoglobin concentration) and an inverse relationship was observed because phenylalanine concentrations increased linearly as levels of blood hemoglobin decreased as shown in Figure 1.

Because the conversion of phenylalanine to tyrosine is catalyzed by the enzyme phenylalanine hydroxylase, which contains iron as an essential component (1) and is principally located in liver and kidney tissue in the rat (6), it was of interest to determine if concentrations of the enzyme were decreased during states of iron deficiency. As shown in Table 2, levels of phenylalanine hydroxylase activity did not differ significantly in the livers of iron deficient rats from levels of hydroxylase activity determined in livers of control animals (fed the iron-deficient diet, but receiving weekly injections of iron dextran) suggesting that the elevated blood phenylalanine levels reported previously in the paper were not the result of decreased phenylalanine hydroxylase activity in the livers of the animals.

Elevated blood levels of phenylalanine have not been shown to be of themselves responsible for the severe mental disturbances seen in the genetically determined disease phenylketonuria and are generally regarded as indicators of the degree of the metabolic disturbance with changes in concentrations of products of alternate routes of phenylalanine metabolism probably producing the toxic effects seen in the disease (2). Although the increases in blood phenylalanine levels observed in the iron-deficient rats are much less in magnitude than the increases observed in phenylketonuria, they may indicate a milder degree of disturbance of phenylalanine metabolism sufficient to produce some of the mild symptoms of impaired mental function previously described in iron-deficient animals and human subjects (7). It is, therefore, of interest to study iron-deficient rats further to determine the cause of the increased levels of blood phenylalanine and whether such increased levels are accompanied by changes in concentrations of other compounds related to impaired phenylalanine metabolism which may disturb mental activity.

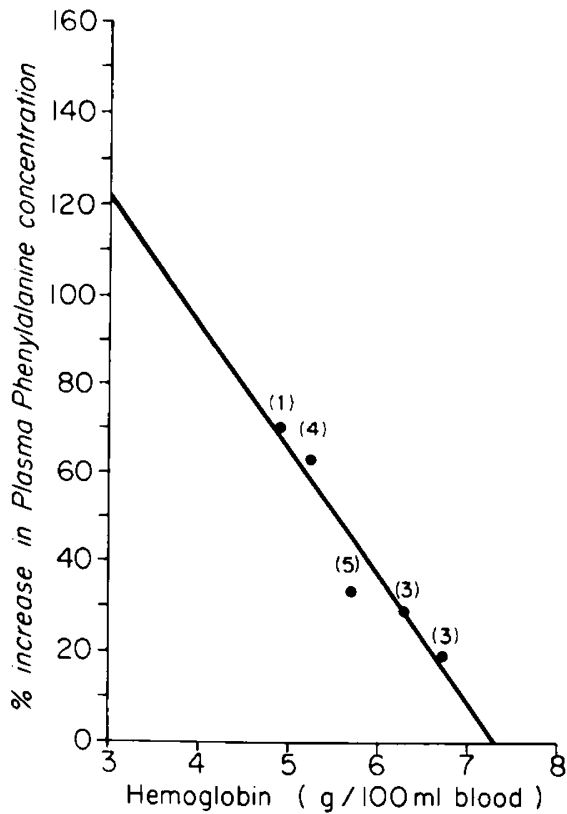

Fig. 1. Relationship between the degree of iron deficiency and plasma phenylalanine concentration. Figures in parentheses represent the number of animals included in the average value.

Table 2. Effects of iron deficiency on phenylalanine hydroxylase activity in rat liver 1

\begin{tabular}{|c|c|c|c|}
\hline \multirow[b]{2}{*}{ State of animal } & \multirow[b]{2}{*}{$\begin{array}{c}\text { Hemoglobin } \\
\mathrm{g} / 100 \mathrm{ml} \\
\text { blood }\end{array}$} & \multicolumn{2}{|c|}{ Phenylalanine hydroxylase } \\
\hline & & $\begin{array}{l}\text { Specific activ- } \\
\text { ity (nmol } \\
\text { phenylalanine } \\
\text { metabolized/ } \\
\text { min/mg pro- } \\
\text { tein) }\end{array}$ & $\begin{array}{l}\text { Activity/g liver } \\
\text { (nmol phenylal- } \\
\text { anine metabo- } \\
\text { lized/min/g } \\
\text { liver) }\end{array}$ \\
\hline Control animals & $14.0 \pm 0.2$ & $5.34 \pm 0.35$ & $526.0 \pm 25.0$ \\
\hline $\begin{array}{l}\text { Iron deficient ani- } \\
\text { mals }\end{array}$ & $6.1 \pm 0.1$ & $6.21 \pm 0.30$ & $596.0 \pm 26.0$ \\
\hline$P$ value & & $P>0.1$ & $P>0.1$ \\
\hline
\end{tabular}
SE.

'Each value represents the mean of experiments on 12 animals \pm the

\section{REFERENCES AND NOTES}

1. Fisher, D. B., Kirkwood, R., and Kaufman, S.: Rat liver phenylalanine hydroxylase, an iron enzyme. J. Biol. Chem., 247: 5161 (1972).

2. Knox, W. E. Phenylketonuria. In: J. B. Stanbury, J. B. Wyngaarden, and D. S Fredrickson: The Metabolic Basis of Inherited Disease. Third Edition. Chap. 11, p. 266-295 (McGraw-Hill Book Co., New York, 1972).

3. Lowry, O. H., Rosebrough, N. J., Farr, A. L., and Randall, R. J.: Protein measurement with the Folin phenol reagent. J. Biol. Chem., 193: 265 (1951).

4. Mackler, B., Person, R., Miller, L. R., Inamdar, A. R., and Finch, C. A.: Iron deficiency in the rat: biochemical studies of brain metabolism. Pediat. Res., 12. 217 (1978).

5. McCaman, M. W., and Robins, E.: Fluorimetric method for the determination of phenylalanine in serum. J. Lab. Clin. Med., 59: 885 (1962).

6. McGee, M. M., Greengard, O., and Knox, W. E.: The quantitative determination of phenylalanine hydroxylase in rat tissues. Biochem. J., 127: 669 (1972).

7. Pollitt, E., and Leibel, R. L.: Iron deficiency and behavior. J. Pediatr., 88: 372 (1976).

8. Snedecor, G. W. and Cochran, W. G.: Statistical Methods. 6th Edition. p. 258298 (lowa State University Press, Ames, lowa, 1974).

9. This research was supported, in part, by grants GM-23006, HD-0596 I, HL-06242 and HD-02274 from the National Institutes of Health.

10. Received for publication March 10, 1978.

I1. Accepted for publication September 7, 1978. 